\title{
PREVALENCE OF INTESTINAL PARASITES IN SLUM AREAS OF SOUTHERN DELHI
}

\author{
DUDEJA M. ${ }^{*}$, NANDY S., DAS A.K., ALAM S. AND TIWARI R. \\ Department of Microbiology, Hamdard Institute of Medical Sciences, Jamia Hamdard, New Delhi- 110062, India. \\ *Corresponding Author: Email- mridududeja@rediffmail.com
}

Received: August 03, 2012; Accepted: September 24, 2012

\begin{abstract}
A retrospective study was conducted during the period of 1st July 2010 to $30^{\text {th }}$ June 2011 in the department of microbiology of HAH centenary Hospital, Hamdard Institute of Medical Sciences, New Delhi. A total of 2907 Stool samples send to the microbiology department from indoor and outdoor patients with gastrointestinal symptoms with or without anemia were analyzed. The patients were mostly from low socio economic strata of Sangam Vihar. 759 samples were positive for parasitic infections. The most common intestinal parasites were found to be E. histolytica (20.22\%), followed by Giardia lamblia (2.68\%) and Ascaris lubricoides (1.4\%). Ova of Hookworm and larvae of Strongyloides stercoralis was found 6 times each. Other common parasitic isolates were Taenia species $(0.1 \%), H$. nana $(0.48 \%)$, Trichuris trichura $(0.1 \%)$ and Trichomonas hominis $17(0.58 \%)$. The study emphasizes on better drinking water and sanitation requirement for the target population.
\end{abstract}

Keywords- Intestinal parasite, Delhi

Citation: Dudeja M., et al. (2012) Prevalence of Intestinal Parasites in Slum Areas of Southern Delhi. International Journal of Microbiology Research, ISSN: 0975-5276 \& E-ISSN: 0975-9174, Volume 4, Issue 8, pp.-312-315.

Copyright: Copyright@2012 Dudeja M., et al. This is an open-access article distributed under the terms of the Creative Commons Attribution License, which permits unrestricted use, distribution and reproduction in any medium, provided the original author and source are credited.

\section{Introduction}

Intestinal parasites are widely prevalent in third world countries due to poor sanitation, inadequate personal hygiene and lack of awareness about safe potable drinking water [1]. Even though parasitic infection is an uncommon cause of mortality, it is estimated that 60 $\%$ of world's population has gut parasites causing significant morbidity. The intestinal parasitic load is considered as a general indicator of the socio-economic status of the region. Contaminated food and water are the major cause of entero-parasite transmission. Lack of proper sanitation and dense population aggravates the problem in the developing countries. In the developing countries it is also a significant cause of nutritional deficiency in the developing countries [2]. The commonest parasite causing infection globally are Ascaris (20\%), hookworm(18\%), Trichuris trichura (10\%) and E. histolytica (10\%) [3]. In India prevalence rate of parasitic infection ranges from $12.5 \%-66 \%$ with varying prevalence rates for individual parasite [4-10].

This present retrospective study aims to analyze the rate of different intestinal parasitic infection in symptomatic patients of different age groups coming to HAH Centenary Hospital in Southern Delhi which mainly caters patients of lower socio economic strata from neighboring areas. The study also tries to find out the rate of multiple infections in this community.

\section{Material and Methods}

A retrospective study was conducted during the period of 1st July 2010 to $30^{\text {th }}$ June 2011 in the department of microbiology of HAH centenary Hospital, Hamdard Nagar, New Delhi. A total of 2907 Stool samples send to the microbiology department from indoor and outdoor patients with gastrointestinal symptoms with or without anemia were analyzed. All samples were subjected to routine microscopic examination by normal saline and lugol's iodine wet mount preparations [11]. The samples were processed within 3 hours of collection. The larva of Strongyloides was identified on the basis of specific morphological details. In case of suspected Strongyloides infection; water emergence semi concentration technique was done. Using a piece of stick a central depression was made into the specimen. It was filled with warm water (not over $37^{\circ} \mathrm{C}$ ). The specimen were incubated at $37^{\circ} \mathrm{C}$ in incubator for approximately $3 \mathrm{hrs}$. Using a micropipette a drop of water was transferred to slide and covered with cover slip. Then the preparation is examined microscopically using 10X objective with the condenser iris closed sufficiently to give good contrast [11]. All findings are recorded according to sex and age group. Cases with co infections were also recorded separately.

\section{Result}

A total of 2097 patient's stool sample was examined macroscopi- 
cally and microscopically. The samples were divided into 6 age groups of 0-6 months, 7 months-5 yrs., 6-20 yrs., 21-40 yrs., 41-60 yrs. and more than $60 \mathrm{yrs}$. These divisions were made keeping in mind the different food habits and lifestyle at different stages of life. Out of all the samples examined, 759 samples were found to be positive for at least one parasite. The most common isolate was $E$. histolytica $(20.22 \%)$ and the least common parasite was $E$. vermicularis, isolated only in two instances [Table-1]. the second most common isolate was G. lamblia $(2.68 \%)$ followed by $A$. lumbricoides $(1.4 \%)$ and $H$. nana $(0.48 \%)$. S. stercoralis was isolated 6 times and there were 17 instances where $T$. hominis was isolated. Infection rate was more common in female patients $(30 \%)$ than male patients $(24 \%)$.

Table 1- Total Parasitic Load

\begin{tabular}{|lccc|} 
Parasites identified & $\begin{array}{c}\text { Total patients } \\
(\mathrm{N}=2907)\end{array}$ & $\begin{array}{c}\text { Male patients } \\
(\mathrm{n}=1896)\end{array}$ & $\begin{array}{c}\text { Female patients } \\
(\mathrm{n}=1011)\end{array}$ \\
\hline E. histolytica & $588(20.22 \%)$ & $344(20 \%)$ & $244(20.6 \%)$ \\
Giardia lamblia & $78(2.68 \%)$ & $46(2.66 \%)$ & $32(2.71 \%)$ \\
Ascaris lubricoides & $43(1.4 \%)$ & $29(1.68 \%)$ & $14(1.19 \%)$ \\
Hookworm & $06(0.2 \%)$ & $05(0.28 \%)$ & $01(.08 \%)$ \\
Taenia species & $03(0.1 \%)$ & $03(0.17 \%)$ & 0 \\
H. nana & $14(0.48 \%)$ & $11(0.64 \%)$ & $03(0.25 \%)$ \\
Trichuris trichura & $03(0.1 \%)$ & $01(0.6 \%)$ & $02(0.16 \%)$ \\
Strongyloides & $06(0.2 \%)$ & $04(0.23 \%)$ & $02(0.16 \%)$ \\
Enterobius vermicularis & $01(0.03 \%)$ & $01(0.06 \%)$ & 0 \\
Trichomonas hominis & $17(0.58 \%)$ & $12(0.63 \%)$ & $05(0.49 \%)$ \\
Total & $759(26.1 \%)$ & $456(24 \%)$ & $303(30 \%)$ \\
\hline
\end{tabular}

$N=$ Total number of samples examined, $n=$ Number of samples examined in male and female.

Among the males of different age group, isolation rate of $E$. histolytica was more or less similar above the age of 7 months, highest $(18.64 \%)$ been in the age group of $6-20$ yrs. [Table-2]. G lamblia was most common in the age group of 7 months $-5 \mathrm{yrs}$. (06.7\%). The age group of 6-20 yrs. showed highest percentage of $A$. lumbricoides infection (03.51\%). Infection by Taenia species was seen in male patients between 21-60 yrs. of age. Hookworm infection was most common in the older age group of 41-60 yrs. (0.95\%).

Table 2- Parasitic Load in Males of different age group

\begin{tabular}{|lcccccc|}
$\begin{array}{l}\text { Parasites } \\
\text { identified }\end{array}$ & $\begin{array}{c}0-6 \text { Mnths } \\
(\mathrm{n}=27)\end{array}$ & $\begin{array}{c}7 \text { M-5yrs. } \\
(\mathrm{n}=118)\end{array}$ & $\begin{array}{c}6-20 \mathrm{yrs} . \\
(\mathrm{n}=370)\end{array}$ & $\begin{array}{c}21-40 \mathrm{yrs} . \\
(\mathrm{n}=894)\end{array}$ & $\begin{array}{c}41-60 \mathrm{yrs} . \\
(\mathrm{n}=316)\end{array}$ & $\begin{array}{c}>60 \mathrm{yrs} . \\
(\mathrm{n}=171)\end{array}$ \\
\hline $\begin{array}{l}\text { E. histolytica } \\
\text { G. lamblia }\end{array}$ & $03(11.1 \%)$ & $19(16.1 \%)$ & $69(18.64 \%)$ & $165(18.45 \%)$ & $58(18.35 \%)$ & $30(17.54 \%)$ \\
A. lumbricoides & 0 & $08(06.7 \%)$ & $11(2.9 \%)$ & $21(02.35 \%)$ & $04(1.26 \%)$ & $02(1.16 \%)$ \\
Hookworm & 0 & 0 & $13(03.51 \%)$ & $09(01 \%)$ & $05(1.58 \%)$ & $02(1.16 \%)$ \\
Taenia spp. & 0 & $01(0.84 \%)$ & 0 & $02(0.22 \%)$ & $03(0.95 \%)$ & 0 \\
H. nana & 0 & $01(0.84 \%)$ & $05(01.35 \%)$ & $04(0.44 \%)$ & $01(0.3 \%)$ & 0 \\
T. trichura & 0 & 0 & 0 & 0 & $01(0.3 \%)$ & 0 \\
Strongyloides & 0 & 0 & $01(0.27 \%)$ & 0 & $03(0.94 \%)$ & 0 \\
E. vermicularis & 0 & $01(0.84 \%)$ & 0 & 0 & 0 & 0 \\
T. hominis & 0 & 0 & $02(0.54 \%)$ & $07(0.78 \%)$ & $03(0.94 \%)$ & 0 \\
Total & $03(11.1 \%)$ & $30(25.4 \%)$ & $101(27.29 \%)$ & $210(23.48 \%)$ & $78(24.68 \%)$ & $34(19.88 \%)$ \\
\hline
\end{tabular}

Mnth/M=months, yrs.=years, $n=$ number of samples examined

In case of female patients the rate of $E$. histolytica infection was comparatively lesser in extreme of ages. Highest rate of infection was seen in the age group of 6-20 yrs. (32.9\%). Similar to male patients, female patients too showed most $\mathrm{G}$. lamblia infection in the age group of 7 months-5 yrs. (08.9\%) [Table-3]. only one female patient showed Hookworm infection. No infection by $E$. vermicularis and Taenia species was seen in female patients.
Table 3- Parasitic Load in Females of different age groups

\begin{tabular}{|lcccccc|} 
Parasites & $\begin{array}{c}0-6 \text { Mnth } \\
\text { identified }\end{array}$ & $\begin{array}{c}7 \text { Mnth-5yrs. } \\
(\mathbf{n}=67)\end{array}$ & $\begin{array}{c}6-20 y r s . \\
(n=194)\end{array}$ & $\begin{array}{c}21-40 y r s . \\
(n=434)\end{array}$ & $\begin{array}{c}41-60 y r s . \\
(n=203)\end{array}$ & $\begin{array}{c}>60 y r s . ~ \\
(n=92)\end{array}$ \\
E. histolytica & $02(9.5 \%)$ & $07(10.4 \%)$ & $64(32.9 \%)$ & $105(24.2 \%)$ & $54(26.6 \%)$ & $12(13 \%)$ \\
G. lamblia & 0 & $06(08.9 \%)$ & $07(03.6 \%)$ & $13(6.7 \%)$ & $05(2.5 \%)$ & $01(1 \%)$ \\
A. lumbricoides & 0 & $02(2.9 \%)$ & $03(01.5 \%)$ & $06(2.9 \%)$ & $01(0.5 \%)$ & $02(2 \%)$ \\
Hookworm & 0 & 0 & 0 & 0 & $01(0.5 \%)$ & 0 \\
Taenia spp. & 0 & 0 & 0 & 0 & 0 & 0 \\
H. nana & 0 & 0 & $01(0.5 \%)$ & 0 & 0 & $01(1 \%)$ \\
T. trichura & 0 & 0 & $02(1 \%)$ & $01(0.2 \%)$ & 0 & 0 \\
Strongyloides & 0 & 0 & $02(1 \%)$ & 0 & 0 & 0 \\
E. vermicularis & 0 & 0 & 0 & 0 & 0 & 0 \\
T. hominis & 0 & 0 & $02(1 \%)$ & $03(0.6 \%)$ & 0 & 0 \\
Total & $02(9.5 \%)$ & $15(22.38 \%)$ & $81(41.75 \%)$ & $128(29.49 \%)$ & $61(29.5 \%)$ & $16(17.4 \%)$ \\
\hline
\end{tabular}

Mnth=months, yrs. = years, $n=$ number of samples examined

There were 25 cases where mixed infection was seen. In all of these cases there were only two parasites involved. The most common co-infection was by E. histolytica and G. lamblia [14], followed by $A$. lumbricoides and $E$. histolytica [7]. [Table-4]. both males and females of age group 6-20 yrs. showed highest number of coinfections (6 each).

Table 4- Mixed Infection in different age groups

\begin{tabular}{|c|c|c|c|c|c|c|c|c|c|c|c|c|c|}
\hline Parasites & $0-6 \mathrm{~N}$ & Inth & Mnt & 5yrs. & $6-20$ & & $21-4$ & yrs & $41-6$ & yrs & $>6$ & & \\
\hline identified & $\mathrm{M}$ & $F$ & M & $\mathrm{F}$ & $\mathrm{M}$ & $F$ & $\mathrm{M}$ & $F$ & M & $\mathrm{F}$ & $\mathrm{M}$ & $\mathrm{F}$ & \\
\hline $\begin{array}{l}\text { A. lumbricoides } \\
+ \text { T. trichura }\end{array}$ & - & - & - & - & 1 & - & 1 & - & - & - & - & - & 2 \\
\hline $\begin{array}{l}\text { E. histolytica + } \\
\text { G. lamblia }\end{array}$ & - & - & 2 & 1 & 5 & 2 & 3 & - & - & 1 & - & - & 14 \\
\hline $\begin{array}{l}\text { A. lumbricoides } \\
+ \text { E. histolytica }\end{array}$ & - & - & - & - & 1 & 3 & 2 & - & 1 & & - & - & 7 \\
\hline $\begin{array}{l}\text { Strongyloides+ } \\
\text { T. trichura }\end{array}$ & - & - & - & - & - & 1 & - & & - & - & - & - & 1 \\
\hline $\begin{array}{l}\text { Strongyloides } \\
+E \text {. histolytica }\end{array}$ & - & - & - & - & 1 & - & - & - & - & - & - & - & 1 \\
\hline Total & 0 & 0 & 2 & 1 & 6 & 6 & 5 & 0 & 1 & 1 & 0 & 0 & 25 \\
\hline
\end{tabular}

Mnth=months, $y r s .=$ years, $M=$ male,$F=$ female

\section{Discussion}

The present study showed only $26.1 \%$ incidence of intestinal parasites in study population, in comparison to the other studies done across the nation. Many of the studies have shown upto $70 \%$ prevalence rate [12-14]. This may be indication of a better sanitation and drinking water facilities in Delhi as compared to other states. But when the results were compared with other studies conducted in and around Delhi, the incidence rate of the present study seemed to be a higher than the average. Singh, et al reported $25 \%$ of incidence in 1993 and Das, et al reported $23.6 \%$ in 2004 [4,15]. This could be attributed to the fact that the target population belonged to the area of Sangam Vihar, one of the bigger slums of India and understandably has less than adequate sanitation and drinking water facility, as compared to most of the other areas of Delhi.

Contrary to many studies across India and world where the percentage of parasitic infection in male patients were more than female patients, the present study showed higher rate of infection among females $(30 \%)$ in comparison to the males $(24 \%)[16,17]$.

The incidence of $E$. histolytica was very high (20\%). This is significant when compared to other studies which showed only $2-3 \%$ isolation rate $[18,19]$. Similar results were found in the study con- 
ducted by Shrihari Narayan, et al [20]. The second most common isolate was Giardia lamblia (2\%) which is significantly lower than the study done by Bisht, et al $(14.8 \%)$ at Ghaziabad which is not very far from the location of present study [21]. The high prevalence of intestinal protozoal infection directly indicated poor sanitary and drinking water conditions of the area in consideration.

Among the helminthes Ascaris lumbricoides was the most common finding $(1.4 \%)$, which was much lower incidence when compared with studies by Bisht, et al $(6.2 \%)$ and Srivastava $(22.2 \%)[21,22]$. There were 14 cases of $H$. nana. Hookworm infection occurs through penetration of skin. We have found only 6 hookworm infection cases which could be attributed to urban lifestyle where people are rarely exposed to soil. Among these 6 cases only 1 was female and rest of the 5 cases were males. Not a single case of Hookworm infection was found in children. It was mainly seen in older age group (>20-60) who are more likely to be exposed to the larvae while walking bare feet in the field. Studies of Sethi, et al and Bisht, et al showed much higher incidence of Hookworm infection [18,21].

The highest rate of parasitic infection was found in the age group of $>5-20$ yrs. (males 27.29\%; females $41.75 \%$ ), which included the school going children and teenagers. Similar result was shown be Gagandeep, et al [1].

Interestingly, we have found five ( 3 in males $\& 2$ in females) cases of $E$. histolytica infection in infants (0-6 months). When only mother's milk is the only prescribed food for infants, this finding indicates the lack of awareness among mothers, which can be attributed to the lower socio-economic status of the area. Rate of infection by $E$. histolytica was nearly similar among the all age groups in males, whereas females the age group of $>5-20 \mathrm{yrs}$. showed the highest rate of incidence $(32.9 \%)$.

We found that prevalence of Giardia lamblia is highest in small children belonging to the age group of $>6$ months $-5 \mathrm{yrs}$. (males $6.7 \%$, females $8.9 \%$ ). Study by Gagandeep, et al showed similar results [1]. The lower rate of protozoal infection in adults could be attributed to acquired immunity attained after repeated attacks.

Among males, the highest rate of helminthic infection was seen in the active age group of $>5-20$ yrs. Similar trends were seen for protozoal infection. But in case of females the highest rate of helminthic infection was seen in the age group of $>20-40$ yrs. Overall number of helminthic infection was more in males compared to females. A similar result was obtained by Wani, et al [23].

Studies done on Trichomonas hominis indicated it to be a possible pathogen [17]. Hence we have included Trichomonas hominis in the list of enteric parasites $(0.58 \%)$. The infection was found more commonly in males as compared to females $(0.63 \%, 0.49 \%$ respectively). Among the females the rate of infection by was seen only in the age group of $>20-40 \mathrm{yrs}$. Sehgal, et al reported $2.3 \%$ isolation rate in pregnant women [24].

Larvae of Strongyloides stercoralis were found in 6 stool samples $(0.2 \%)$. A similar study by Devi, et al in Assam found a higher isolation rate of $8.5 \%$ [25].

Our study also showed 25 cases of mixed infection $(0.01 \%)$. All the 25 cases were caused by 2 parasites. A study conducted by Wongstitwilairoong, et al in Thailand showed a much higher rate
(18.5\%) of co-infection [26]. The commonest mixed infection was of E.histolytica and Giardia lamblia (14 out of 25 cases). This is a significant finding and indicates a very low level of drinking water facility. Again the age group of $>5-20$ yrs. had the higher rate of co infection (48\%).

Parasitic infections are indicators of the quality of drinking water and sanitation in a society. Conducted over a year, a very large number of samples (2907) were included in this study. The patients mostly belonged to one of the largest slums of Delhi. The study clearly indicated a comparatively low sanitation and drinking water facility in that area as compared to other parts of Delhi. Hence there is substantial need to regulate living standards in the poorer sections of the city. The study highlights the need of spreading awareness regarding the spread enteric parasitic infection through contaminated water. School going children should be made aware of the hazards of eating food at open stalls and drinking random tap water. Moreover there is need to educate mothers about feeding strategies of infants and very young children. As a whole the study indicates the need of greater interest in part of local civic body towards spreading awareness and providing better drinking water and sanitation facility in these poorer sections of the community amidst the quintessential metropolis.

\section{References}

[1] Kang Gagandeep, Mathew Mary S., Prasanna Rajan D., Daniel Jasper D., Mathan Minnie M., Mathan V.I., Muliyil J.P. (19980 Trop. Med. Int. Health, 3, 70-75.

[2] Patel J.C. (1986) J. Postgrad. Med., 32, 219-24.

[3] World Health Organization (1987) WHO Technical Reports Series, 749, 1-86.

[4] Das S., Saha R. and Singhal S. (2007) Indian J. Community Med., 32, 27-31.

[5] Gadgil S.D., Kulkarni S.S., Apte V.V. and Nanivadekar A.S. (1984) J. Postgrad. Med., 30, 137-143.

[6] Sharma R.D., Bansal R.D., Sharma A.N. (1975) J. Ind. Med Assoc., 64(10), 255-8.

[7] Sinha A.K. and Sahai B.N. (1977) Ind. J. Public Health, 21, 2933.

[8] Sanyal S.C., Gaur S.D., Shrivastava D.L., Sen P.C., Marwah S.M. and Singh H. (1972) Indian J. Med. Res., 60(7), 979-86.

[9] Sen R. (1968) Indian Journal of Medical Research, 56, 13711380.

[10]Chowdhury A.B. and Schiller E.L. (1968) American J. of Epidemiol., 87, 299-306.

[11]Cheesbrough M., District Laboratory Practice in Tropical Countries, 1, 214-215.

[12]Singh P., Gupta M.L., Thakur T.S., Vaidya N.K. (1991) Indian J. Med. Sci., 45(8), 201-4.

[13]Rao V.G., Yadav R., Bhondeley M.K., Das S., Agarwal M.C. and Tiwari R.S. (2002) J. Com. Dis., 34,100-105.

[14]Singh H.L., Singh N.B. and Singh Y.I. (2004) J. Com. Dis., 36, 111-116.

[15]Singh S., Raju V.G. and Samathray J.C. (1993) Tropical Gas- 
troenterology, 149(3), 104-108.

[16]Singh D.S., Chandani R.R., Kumar S., See Catt J.S., Srivastava P.K., Udupa K.N. (1984) Indian J. Prev. Soc. Med., 15, 1-8.

[17]lbrahim A.H. (2002) Ann. Saudi Med., 22, 273-75.

[18]Sethi S., Sehgal R., Malla N., Dudey M.L. and Mahajan R.C. (200) Ind. J. Med. Microbiology, 18(3), 106-109.

[19]Norhayati M., Fatmah M.S., Yusof S., Edariah A.B. (2003) Med. J. Malaysia, 58(2), 296-305.

[20]Narayan S., Kumudini T.S., Mariraj J. and Krishna S. (2011) J. Pharma. Biomed. Med. Science, 12(08).

[21]Bisht D., Verma A.K., Bharadwaj H.H.D. (2011) Trop. Parasitology, 1(2), 104-107.

[22]Shrivastava J.B. (1977) Indian J. Med. Res., 21, 29-33.

[23]Wani S.A., Ahmad F., Zargar S.A., Fomda B.A., Ahmad Z., Ahmad P. (2007) Ind. J. Med. Micro., 25(4), 398-400.

[24]Sehgal R., Reddy G.V., Verweij J.J., Subba Rao A.V. (2010) Rev. Inf., 1(2), 100-103.

[25]Devi U., Borkakoty B., Mahanta J. (2011) Trop. Parasitol., 1, 30 -32 .

[26]Wongstitwilairoong B., Srijan A., Serichantalergs O., Fukuda C.D., Mcdaniel P., Bodhidatta L., Mason C.J. (2007) Am. J. Trop. Med. Hyg., 7(62), 345-350. 